\title{
Experiências de estudantes em processo de aprendizagem de língua inglesa: por mais transparência
}

\author{
EFL students' classroom experiences: in pursuit of \\ transparency
}

\section{Laura Stella Miccoli Universidade Federal de Minas Gerais}

\section{Summary}

Students' experiences as learners of English in a brazilian university classroom have been documented, exposing the complexity of classroom foreign language learning (MICCOLI, 1997, 2001, 2003, 2004). In the inner dimension, i.e, inside the classroom, learning opportunities given by the teacher originate direct classroom experiences. In the outer dimension, i.e, outside the classroom, the context in which the class occurs and whatever else might have happened before also influence learners in class, constituting the indirect classroom experiences. This article presents analysis and categorization procedures, exemplifying them. Our intention is to stimulate further research on other learners' experiences in different types of classrooms to strengthen Foreign Language Learning Research in Applied Linguistics.

\section{Keywords}

Experiences, students, EFL classroom. 


\section{Resumo}

As experiências de estudantes universitários de inglês em processo de aprendizagem em uma sala de aula têm sido documentadas, expondo a complexidade desse processo (MICCOLI, 1997, 2001, 2003, 2004). Na dimensão interna, i. e., dentro de sala de aula, as oportunidades de aprendizagem oferecidas pelo professor dão origem às 'experiências diretas'. Na dimensão externa, i.e., fora da sala de aula, tanto o contexto no qual a aula acontece bem como tudo aquilo que possa ter acontecido antes constituem as 'experiências indiretas'. Este artigo apresenta os procedimentos de análise e categorização dessas experiências, exemplificando-as. Nossa intenção é estimular a realização de outras investigações no campo das experiências de estudantes em processo de aprendizagem de inglês em salas de aula no Brasil tanto para ampliar o conhecimento sobre a sala de aula para fortalecer a pesquisa sobre o ensino e aprendizagem de língua estrangeira na lingüística aplicada.

\section{Palavras-chave}

Experiências, estudantes, sala de aula de inglês. 


\section{Introdução}

$\mathrm{F}$

oi-se o tempo em que se pensava o processo de aprendizagem como um processo essencialmente cognitivo e individual. A abordagem behaviorista ao ensino e à aprendizagem de línguas está superada. O que prevalece hoje em dia é uma concepção da aprendizagem como um processo complexo em que a dimensão cognitiva se alia à dimensão sociocultural, que merece a atenção de pesquisadores (LANTOLF, 2000) em busca de uma melhor compreensão do processo de ensino e aprendizagem de línguas. É nesse contexto da lingüística aplicada ao ensino de línguas estrangeiras que se localiza meu interesse nas experiências.

Minhas pesquisas sobre experiências de estudantes e professores têm por objetivo investigar como as vivências em sala de aula contribuem para compreender melhor a natureza sociocultural do processo de ensino e aprendizagem de língua inglesa (MICCOLI, 2000, 2001, 2003, 2004 e no prelo). Através dessas pesquisas e das dissertações e teses que tenho orientado, os diferentes tipos de experiências em sala da aula vêm sendo confirmados bem como a importância das vivências externas à sala da aula para a compreensão do que acontece no processo de ensino e aprendizagem dentro (MATTOS, 2000; CONCEIÇÃO, 2004; PORTO, 2003), ou fora da sala de aula (NEFFA, 2004; CUNHA, 2005).

Entretanto, apesar de ter publicado sobre as experiências vivenciadas por estudantes dentro da sala de aula como experiências diretas de natureza cognitiva, social e afetiva, e as externas à sala de aula como experiências indiretas de natureza contextual, pessoal, conceitual ou futura (MICCOLI, 2000, 2001) e em vista da importância de se trabalhar com experiências para a transformação de perspectivas e de experiências (FREITAS, 2004; ARAGÃO, 2005; MICCOLI, 2006, 2007 ), faz-se necessário detalhar os procedimentos para sua categorização, bem como revelar o conteúdo dessas experiências com o objetivo de dar mais transparência ao seu teor e divulgar a taxonomia resultante para uso de outros pesquisadores. Assim, neste artigo descrevo não só o processo de classificação de experiências em categorias, como também o detalhamento das 
subcategorias, apresentando as experiências que revelam como os estudantes vivenciam o que acontece em sala de aula.

\section{A Categorização de Experiências e a Busca da Confiabilidade}

A necessidade de categorizar as experiências relatadas para uma melhor compreensão das descrições e interpretações sobre o que acontece na sala de aula de língua inglesa emergiu da ausência de estudos que tratassem das experiências de estudantes. Os procedimentos que Donato e McCormick (1994) utilizaram para a análise de portifólios foram adotados na análise de transcrições de entrevistas com estudantes (MICCOLI, 2000, 2001, 2003, 2004), seguindo os passos sugeridos por esses autores.

Primeiramente, de posse das transcrições, passa-se à sua leitura com o objetivo de identificar os temas que se encontram nas experiências relatadas pelos estudantes. Dessa forma, uma pergunta guia esse estágio da análise dos dados: o que se encontra nos dados? A resposta a essa pergunta gera uma listagem de temas, incluindo tanto os mais quanto os menos freqüentes. Logo depois, a partir dessa listagem, faz-se um agrupamento de temas por campos de experiência. Nesta etapa da análise dos dados, uma segunda pergunta-guia está implícita: os dados podem ser agrupados? A resposta a essa pergunta leva a diferentes agrupamentos que precisam ser claramente identificados. Isso exige uma nova leitura dos agrupamentos para que se passe à busca de um nome que possa sintetizar o conteúdo de cada agrupamento da melhor maneira possível. Nesta penúltima etapa, a pergunta-guia é: qual é o melhor nome para este agrupamento? A resposta a essa pergunta leva às diferentes categorias de experiências. No entanto, cada agrupamento, agora devidamente nomeado, pode se referir a diferentes experiências da mesma natureza. Dessa forma, passa-se à última fase da análise dos dados de cada agrupamento, buscando organizar as experiências da mesma natureza. Nesta fase final, a pergunta-guia é: qual é a melhor maneira de organizar e de nomear as experiências dentro de cada categoria? A resposta a essa pergunta explicita as diferentes subcategorias que compõem cada categoria de experiências.

Em relação às subcategorias, em vista de os temas serem muitos e variados, o princípio ‘sete mais ou menos dois' de Miller (1956) foi seguido. Esse princípio diz que nossa capacidade de processar informações é limitada. Pelo princípio do sete mais ou menos dois, processaríamos informações no limite de 
cinco a nove pedaços de informação por unidade significativa. Dessa forma, não ultrapassamos o limite de sete em subcategorias para garantir o processamento dessas experiências como unidades significativas.

Tendo categorizado as experiências dessa forma, surge a primeira versão da categorização das experiências em sala de aula (Anexo1). Nesse momento, é importante testar a confiabilidade da categorização para "proteger nossa pesquisa e a construção de teorias de nossos entusiasmos" (LATHER, 1986, p. 67). Para esse teste, foram seguidos alguns procedimentos.

Primeiramente, pede-se ajuda a um colega que atuará como juiz da categorização desenvolvida. Apresenta-se a esse juiz uma descrição das categorias e subcategorias com exemplos retirados dos dados. A seguir, selecionase $10 \%$ dos dados para que o juiz os codifique, utilizando a categorização desenvolvida. Antes disso, recomenda-se que se utilize uma outra amostra menor dos dados para uma sessão de treinamento, já que a codificação será uma tarefa mais difícil para o juiz que não tem o conhecimento profundo dos dados que o pesquisador tem. Depois, deixa-se o juiz categorizá-los independentemente. $\mathrm{O}$ pesquisador codifica também a mesma amostra dos dados para fins de comparação.

O próximo passo é verificar até que ponto há concordância entre a categorização feita pelo juiz e a feita pelo pesquisador. Como se trata de dados qualitativos, seria ideal se a concordância entre pesquisador e juiz chegasse a $80 \%$. Caso não se chegue a esse índice na primeira vez, recomenda-se selecionar nova amostra e fazer outra codificação até que se chegue perto desse índice. No caso das experiências de sala de aula dos estudantes de Letras, esse procedimento teve um índice de concordância de $85 \%$. Além disso, um espaço de tempo entre a codificação inicial e uma codificação posterior é mais uma forma de testar a consistência do pesquisador em codificar os dados e, conseqüentemente, a confiabilidade da categorização. Em relação à codificação das experiências dos estudantes, esse índice foi de $92 \%$.

Em consequiência dos procedimentos de verificação da sua confiabilidade, a versão final da categorização das experiências foi aperfeiçoada. Dois ajustes foram feitos: a reescrita das descrições de categorias e subcategorias responsáveis por algumas das discrepâncias de codificação entre pesquisador e juiz e a revisão do número de subcategorias, buscando deixar apenas as representativas. Esses ajustes, o índice de $85 \%$ de concordância entre 
pesquisador e juiz e o índice de $92 \%$ de consistência interna na codificação do pesquisador nos dão segurança para apresentar a versão final da categorização das experiências de estudantes em sala de aula de língua inglesa, explicitando essas experiências através dos excertos de relatos de estudantes em diferentes pesquisas (MICCOLI, 2000, 2001, 2003 e 2004).

\section{As Experiências em Sala de Aula de Estudantes de Língua Inglesa}

Como já mencionado, as experiências em sala de aula (ESA) dividem-se em experiências diretas e indiretas. As diretas são internas à sala de aula e de natureza cognitiva, social e afetiva. As indiretas são externas à sala de aula e de natureza contextual, pessoal, conceptual ou futura. Nosso objetivo é descrever o conteúdo de cada categoria e respectivas subcategorias, ilustrando a descrição com dados.

\section{Experiências Cognitivas}

Esta é a primeira das três experiências diretas na sala de aula. Os critérios para se codificarem as experiências nesta categoria são: (1) a experiência tem que ter origem na sala de aula, referir-se à experiência nesse contexto e (2) referir-se ao processo de aprendizagem em seu aspecto cognitivo, i.e., o processo de aprender, entender e adquirir conhecimentos.

Na categoria das experiências cognitivas estão as percepções dos alunos em relação (1) às atividades de sala de aula, (2) aos objetivos, às dificuldades e dúvidas em relação às atividades de sala de aula, (3) à sua participação e ao seu desempenho nas atividades, bem como (4) à aprendizagem que decorre delas, (5) ao ensino dessas atividades, (6) aos assuntos relacionados às atividades e (7) as estratégias de aprendizagem utilizadas para aproveitar ao máximo essas atividades. Cada uma dessas subcategorias é apresentada a seguir e ilustrada em itálico com dados dos relatos dos estudantes.

\section{Cog. 1. Experiências nas Atividades em Sala de Aula}

Nesta subcategoria estão os relatos que se referem às percepções sobre atividades em sala de aula. Podem se referir especificamente a tarefas em que 
o professor pede aos alunos para completar, ouvir, ler, escrever, falar ou a atividades de apresentação dos estudantes.

Você se saiu bem?

Acho que sim. Eu só gostaria de participar mais. Mas, é tão rápido. A atividade é muito boa; produtiva. Ela (a professora) poderia ter trazido um artigo de um jornal, mas como ela tem que dar tudo depressa porque temos pouco tempo, a gente fica com vontade de participar mais, de aprender mais, discutir mais para que eu possa aprender mais vocabulário. Eu preciso disso.

\section{Cog. 2. Identificação de Objetivos, Dificuldades e Dúvidas}

Nesta subcategoria estão os relatos que se referem às percepções que se referem a (1) identificação de objetivos; (2) dificuldades e (3) dúvidas no processo de lidar com as atividades em sala de aula.

A gente estava conversando sobre listas, o que precisávamos comprar. Então eu pude observar porque a gente lê, né? Então, então estava na lista, o futuro que a gente planeja, futuro como uma intenção e ela explicou isso, quando a gente usa palavras contáveis e não contáveis. (objetivo da atividade)

Mais exercícios. Foi assim: ela explicou e perguntou: 'entenderam? Então, vocês podem fazer os exercícios'. Aí depois, a gente vê que a gente não entendeu. Porque quando eu cheguei no fim da página, eu tive dificuldade de fazer. Pode até ser fácil quando você está praticando, mas depois... (dificuldade).

Nesta atividade eu estava na dúvida sobre 'could I get some stamps?' porque a gente sabe essas regras que dizem... por exemplo, de repente vc vê uma interrogativa com some, como é que pode?! (dúvida)

\section{Cog. 3. Experiências de Participação e de Desempenho}

Nesta subcategoria estão os relatos que se referem às percepções sobre a participação e o desempenho nas atividades em sala de aula. Participação tem a ver com experiências mais passivas em relação a uma atividade, tais como: 
prestar atenção ou acompanhar uma leitura. O desempenho demonstra um envolvimento ativo numa tarefa, tais como: entrar em uma discussão, contribuir para o desenvolvimento da atividade através de respostas às perguntas do professor ou ser voluntário.

Naquela hora eu estava olhando para meu livro, procurando aquele verbo 'ought' para ver se a gramática falava dele. Eu queria descobrir o que ele significa. Depois eu perguntei para a professora. (participação)

Eu acho que essa atividade foi mais interessante porque estava mais perto da nossa realidade. Nós trabalhamos em grupos, eu até me lembrei de um filme; mudança de hábitos; e aqui parece ((incompreensivel)) e as perguntas se eles eram bonitos. Eu respondi que eles eles eram feios. Eu até questionei isso... Então, eu gostei dessa aula, mais relaxante... novas palavras. (desempenho)

\section{Cog. 4. Experiências de Aprendizagem}

Nesta subcategoria estão incluídas as experiências que refletem o que os estudantes aprenderam numa determinada atividade, que podem ser de natureza genérica, como: 'Eu aprendi sobre estereótipos', ou específica, do tipo: 'eu aprendi a expressão hang on'.

Ah... eu aprendi sim. Eu aprendi sobre ser hospitaleira ((incompreensivel)), que a gente tem que usar as nacionalidades... ahn... até o vocabulário que está aumentando quando nós conversamos, né? Eu aprendi sobre estereótipos. Eu aprendi essas coisas. (genérica)

Então eu pude melhorar e com o segundo texto I vi que a preposição em português é usada diferentemente. Então, essa é uma outra coisa que eu aprendi naquele dia. (específica)

\section{Cog. 5. Percepção do Ensino}

Esta subcategoria contém as experiências que refletem como os estudantes percebem o ensino na sala de aula. As experiências podem ser 
positivas ou negativas, podem incluir críticas ou a sugestão de uma abordagem diferente. Podem ainda se referir à maneira como o professor propôs alguma atividade ou à alguma explicação dada pelo professor.

Ela estava... nós vimos o vocabulário, ela falou das horas, tudo. Mas, eu tive algumas dúvidas quando ela começou o poema; algumas palavras que indicavam tempo eu não conhecia. Eu achei que era muito subjetivo. Ela tinha que ter nos dado um tempo para analisar antes, entender, essas palavras literárias.

Eu achei super interessante na última aula quando a professora colocou todas as regras no quadro. Isso que eu já te falei que eu considero super importante. Ela nos deu as regras do uso do indirect speech e dos verbos que usar. Isso eu acho ótimo pra te ajudar quando você tem que fazer. Achei ótimo; ver como é feito, como é usado. Foi muito bom para mim. Essas são as coisas que na aula dela estão me ajudando a entender $o$ que ela está dando.

\section{Cog. 6. Experiências Paralelas às Atividades de Sala de Aula}

Nesta subcategoria estão incluídas as experiências que se referem a questões da aprendizagem paralelas às atividades de sala de aula, tais como: (1) deveres de casa, (2) os materiais usados pelo professor-fitas, livros e (3) provas e testes.

Depois disso, ela perguntou para a turma se vocês tinham feito o dever de casa. Você tinha feito?

Tinha sim. I li tudo e pude ver a diferença entre os dois textos.

Eu fui muito bem na prova, apesar de ter achado ela longa e um pouco complicada, mas acho que me dei bem.

\section{Cog. 7. Estratégias de Aprendizagem}

"Estratégias de aprendizagem" é uma terminologia genérica, que se refere a experiências dos estudantes para aumentar a aprendizagem, tais como: (1) expansão de uma atividade, (2) complementação de atividades (3) prestar atenção, (4) usar regras de gramática, (5) memorizar, (6) tomar notas, (7) fazer perguntas. 
E como é que vocês fizeram nesse caso? Se vocês acharam o material limitado; como é que vocês chegaram ao que vocês queriam?

Nós criamos. Em algumas partes nós tínhamos que conversar em português para achar o que íamos dizer, certo? Então a gente olhou as palavras no dicionário e tentamos usá-las nas frases que a gente falou, certo?

\section{Experiências Sociais}

Esta é a segunda das três categorias diretas. Para classificar experiências nesta categoria, é preciso atender aos seguintes critérios: (1) têm que ter origem na sala de aula e têm que se referir ao domínio social, i.e., para as maneiras como a interação se organiza e à maneira como professor e estudantes se relacionam.

Nesta categoria se incluem as experiências sobre: (1) interação, i.e., sobre a comunicação e o trabalho com outros; (2) tensões nas relações interpessoais entre professor e estudantes ou entre estudantes (3) como os estudantes percebem a si mesmos como estudantes de inglês, (4) o professor em seu papel, (5) os grupos que se formam em sala de aula, seus membros e como esses grupos se relacionam com outros grupos, (6) a sala de aula como uma entidade pessoal e, finalmente, (7) as estratégias de lidar com a competição em classe.

\section{Soc. 1. Interação e Relações Interpessoais}

Nesta subcategoria se incluem as experiências na interação durante a comunicação ou no trabalho, além das relações interpessoais que compõem a vida social entre professor e estudantes e entre colegas.

É por isso que eu contei para você que a gente vê nosso desenvolvimento. Eu fico observando os outros porque a gente está junto desde o primeiro semestre. Então a gente já é um grupo e a gente até sai juntos, um liga pro outro; a gente já se conhece.

Porque eu tentei uma vaga para a seleção no Centro de Extensão e eu não passei. Eu fiquei chateada e pensei 'não vou tentar mais'. Mas, o povo começou a falar comigo 'anda, não desiste não; você está bem; tenta de novo' e coisas assim. Esse apoio foi legal. 


\section{Soc. 2. Tensão nas Relações Interpessoais}

Nesta subcategoria estão as experiências negativas da interação em sala de aula, durante a comunicação ou no trabalho. Temas como competição, críticas, riscos ou exposição negativa aparecem nesta subcategoria.

Então eu fico esperando que alguém responda... porque eu sei que tem gente com dificuldades. Mas, eu estudei isso. Então, acabei respondendo e minha colega falou' humm, mas ela sabe tudo!' Aí eu fico tenso, fico com medo do que as pessoas pensem que eu quero falar; que eu sou o melhor da sala; que eu sou bom aluno; que eu sei todas essas coisas. Por isso, eu fico quieto, evitando responder muito; pra que a turma não pense que eu estou querendo aparecer... na sala de aula

Eu acredito que as outras meninas estavam com medo. Estavam com medo de falar, mas eu não as conheço bem. Mas, do que eu conheço delas, elas assumem riscos. Elas não estão nem aí! Em sala, elas falam, elas perguntam, mesmo que errado, elas falam mesmo. Elas não se importam, (com o que os outros vão dizer), entendeu?

E na quarta passada a turma toda ficou brava com ela. Você não estava lá. Você perdeu. Você tinha que ter estado lá para ver.

\section{Soc. 3. Experiências como Estudante}

Nesta subcategoria se incluem as experiências sobre como os estudantes vêem a si mesmos em sala de aula ou sobre o que é esperado deles em classe.

E é isso que eu gosto na nossa aula de inglês. Lá eu sinto que eu sou um dos melhores alunos. E é isso que eu estou te contando: eu não falo para que os outros não pensem que eu sou cedeéfe ((risos)). Eu não gosto disso; é muito ruim. Puxa! Como estou falando hoje, hein?

\section{Soc. 4. Experiências do Professor}

Nesta subcategoria estão contidos os trechos que se referem a experiências sobre o papel do professor como aquele que tem o manejo da sala de aula. Outras 
experiências incluídas nesta subcategoria são as que se referem ao "poder" possuído pelo professor na sala de aula.

Desse jeito, ela fala para estudar, estudar para a prova, coisas assim. E quando ela nos disse que ia dar a prova do livro todo, eu quase tive um ataque... Ele não ensinou o livro todo para nos testar... Ela disse pra um colega que as notas foram de 7 a 17 ... Isso pra gente... quer dizer, a gente estuda e ... isso cria tanta tensão na sala, né? Aí todo mundo fica falando que ela é legal, mas parece que ela quer nos ferrar... as pessoas tão falando isso.

Você sabe disso, né? Quando um professor te pede pra fazer alguma coisa e você tem que falar, você acaba fazendo, entendeu? De uma certa..., é mais confortável... esperar pelos outros. Então, quando eu vi que ela dividiu os grupos e nos pediu pra responder, a gente ficou mais motivado. Ela até falou com as pessoas: Você faz isso, você faz aquilo, você faz esse outro, entende? Isso é bom.

\section{Soc. 5. Experiências em Grupos ou em Dinâmicas de Grupo}

As experiências que se referem aos assuntos relacionados às interações em grupo estão nesta subcategoria. Os assuntos específicos que se podem encontrar aqui são experiências com trabalhos em duplas e em grupos, ou mesmo experiências com membros do grupo e/ou as divisões dentro deste. Além disso, experiências que registram a dinâmica de trabalho no grupo estão nesta subcategoria.

Eu conversei com minha colega. Não durante a aula toda porque ela nos pediu pra trabalharmos em grupo. Mas, nós conversamos sim.

Porque a gente já se conhece. Você pode observar que a gente está sempre sentando um perto do outro. Ai, as vezes, parece que têm uma provocação; eles ficam olhando pra gente, aquele grupo de lá... aquele grupinho. Eu acho que existe (uma competição) sim porque a gente vê isso claro... Então a gente essa relação; eu vou na casa deles, eles vêm na minha, a gente sai, almoça junto... é diferente a gente já tem uma relação que extrapola a sala de aula. 
Eu estou acostumado a fazer trabalho em grupo na aula de literatura e é mais fácil desse jeito. Você não tem só sua opinião, tem as dos outros, que dizem 'eu não concordo com você', entende? As vezes sua opinião não é a certa; é só em parte.

\section{Soc. 6. Experiências em Turma}

As experiências que se referem à turma, como uma entidade que se comporta e reage como uma unidade, estão nesta categoria. Experiências desse tipo se referem à turma como quieta ou participativa. Há ainda os que falam do 'clima' na turma ou de seu comportamento apático.

As pessoas sempre esperam que os outros respondam primeiro? Eu acredito que sim. Não sei explicar bem para você. Não sei porque a turma não responde... Não sei se é porque tem dúvidas... Não sei.

A turma nesse dia estava agitada, né?Era porque ia ter prova naquela semana.

\section{Soc. 7. Estratégias Sociais}

A última subcategoria das Experiências Sociais contém as experiências que se referem a como os estudantes lidam com questões como competição ou críticas na sala de aula. Algumas experiências revelam critérios para participação, bem como decisões a respeito de como evitar conflitos.

O que eu estou tentando fazer é assim: meu colega está do meu lado e ele me pergunta alguma coisa. Em vez de responder eu falo: 'pergunta pra professora' Então eu estou tentando fazer aqueles que não falam começar a falar. Se eu sou a única a abrir a boca, fica chato.

Mesmo que eu queira falar, eu não falo nada. Porque se eu falar, a turma vai achar que eu sou cedeéfe. Às vezes que quero muito falar, usar uma expressão diferente, mas eu fico na minha, pra não parecer que eu sei tudo. 


\section{Experiências Afetivas}

Esta é a última categoria das experiências diretas. Da mesma forma que as duas outras categorias, para que uma experiência possa ser incluída nesta, é necessário que ela obedeça a dois critérios: (1) é necessário que ela tenha origem na sala de aula; e (2) é necessário que ela se refira ao lado afetivo ou emocional de se estar em classe.

As subcategorias das experiências afetivas se remetem a sentimentos (1) negativos ou positivos; (2) de motivação, interesse, esforço; (3) de auto-estima, (4) às atitudes do professor e, por último, (5) às estratégias afetivas, i.e., como os estudantes lidam com o estresse e/ou com sentimentos negativos, como a frustração, desânimo, etc.

\section{Afe. 1. Experiências de Sentimentos}

Nesta primeira subcategoria afetiva, os sentimentos prevalecem, desde aqueles negativos, tais como a ansiedade, o medo, a frustração, a inibição, a tensão, os nervosismos, o isolamento, a vergonha e o estresse, até os positivos como a sensação de conforto, bem-estar, felicidade e ânimo.

E como é que você lida com isso? Porque pelo que você me conta você se sente frustrada... Você gostaria de participar e não participa... Como é que você resolve esses sentimentos?

Eu nem sei se eu os resolvo. Eu acho que não, porque eu renuncio a alguma coisa que é minha, que é participar para mostrar que eu sei e eu ainda acho que eu tenho muito pra melhorar. Nessa aula, eu respondi, ninguém falou, então eu falei. Então quando eu posso falar, eu me sinto bem. Mas, eu também me sinto frustrada porque eu não posso mostrar que eu sei, entende? Eu não posso falar: 'ah, isso eu sei!'

Eu me sinto mais à vontade nesta sala. Quando eu vou pra aula de Literatura eu quase morro. Lá eu não posso abrir a boca.

\section{Afe. 2. Experiências de Motivação, Interesse e Esforço}

Esta subcategoria inclui as experiências que se remetem (1) à sua motivação pessoal ou à motivação de seus colegas, (2) aos interesses ou ao 
desinteresse dos estudantes em relação às atividades em sala de aula e (3) ao seu esforço ou ao esforço dos colegas para aprender.

Eu vejo que ele é muito desinteressado. Tanto que a professora sempre tem que chamar a atenção dele pra acordar. Ela chama a atenção dele muito em sala.

Mas isso é o que eu vejo: a gente tem que se esforçar. Eu vejo que eu tenho me esforçado, estudando em casa, todos os dias. Às vezes eu até começo a conversar em inglês em casa sozinha.

\section{Afe. 3. Experiências de Auto-estima e Atitudes Pessoais}

As experiências nesta subcategoria revelam como eles se vêem, i.e., sua auto-estima, personalidade e suas atitudes em relação ao processo de aprendizagem.

Não sou tímida porque eu já tenho magistério. Eu já dei aulas pra crianças. Já dei aulas para adultos também. Então, nessa área ((falar em público)) eu não tenho problemas.

\section{Afe. 4. Atitudes do Professor}

Nesta subcategoria estão as experiências que se remetem às atitudes do professor sob o ponto de visto do aluno, i.e., os sentimentos do professor em relação à sala de aula e aos seus alunos.

As pessoas precisam de amizade, estar junto: ninguém é uma ilha... nem o professor. Se os professores acham que os alunos não notam quando eles estão com raiva ou frustrados eles estão enganados. Nós sabemos quando os professores querem acabar com os alunos. A gente sente no ar. Claro que temos que aprender, mas há coisas que os professores nem percebem.

\section{Afe. 5. Estratégias Afetivas}

A última subcategoria afetiva classifica as experiências que se referem a como os estudantes lidam com os sentimentos que emergem da dinâmica da sala de aula. 
A gente está aqui para se formar professor, né? Isso é que está causando toda essa minha tensão. Porque só temos mais três semestres para terminar o curso e a gente não sabe nem a metade do que deveria. É por isso que eu estou prestando muita atenção em sala de aula, porque eu estou ficando desesperada.

Então eu disse pra ela que ia esquecer desses sentimentos de frustração por um tempo. Ela disse que essa lição era de um tópico difícil então ela ia ensinar mais devagar. Então eu disse que ia prestar atenção e responder.

Termina aqui a apresentação das categorias de experiências diretas, i.e., as cognitivas, as sociais e as afetivas, cujas subcategorias revelam os diferentes níveis de experiências que têm origem na sala de aula. As demais experiências relatadas por estudantes são externas à sala de aula, mas têm influência sobre o que nela acontece. Por esse motivo, as próximas categorias de experiências são consideradas indiretas e sua natureza pode ser contextual, pessoal, de crenças ou de metas.

\section{Experiências Contextuais}

Esta é a primeira das experiências indiretas. As experiências contextuais incluem as referências ao ambiente em que a aprendizagem acontece. No nível micro, a instituição é o ambiente em que se encontram os estudantes e que constitui a primeira subcategoria - dos fatores institucionais que influenciam o estudante e sua aprendizagem, tais como: procedimentos de matrícula, requisitos e pré-requisitos, outros cursos e as notas. Fora da universidade, no nível macro, experiências que se remetem ao status da língua inglesa no Brasil, ao mundo real externo à universidade e à especificidade do processo de aprendizagem de uma língua estrangeira no Brasil. Outras experiências que se referem ao contexto estão incluídas nesta categoria, tais como: as repercussões de uma pesquisa no processo de aprendizagem e a questão tempo como um fator do contexto que afeta o processo de aprendizagem em sala de aula. As subcategorias buscam refletir essas experiências. 


\section{Con. 1. Experiências Institucionais}

Aqui ficam as experiências que se referem à instituição onde se encontram os estudantes. Experiências com procedimentos de matrícula e requerimentos institucionais são exemplos típicos das experiências nesta subcategoria.

Por exemplo, alguns dos meus colegas e eu marcamos o dia para vir fazer matrícula para podermos ficar todos juntos na mesma sala no próximo semestre. Se a gente não fizer isso, a gente entra numa nova sala a cada início de semestre e isso não é bom, né?

Essa FAE (Faculdade de Educação)... a gente perde tanto tempo. A gente tem que escrever monografias, trabalhos, a gente tem que se deslocar pra ir até lá... é uma perda de tempo.

\section{Con. 2. Experiências relativas à Língua Estrangeira}

Nesta subcategoria estão as experiências que se remetem ao status da língua estrangeira ou às particularidades do estudo da língua inglesa no Brasil.

Vou ser sincera, às vezes eu acho que o inglês é uma língua elitista, que eu me pergunto 'só a elite pode estudar inglês?' 'Só a elite vai saber inglês?'

Você começa a pensar: 'Meu Deus, eu nunca viajei ao exterior. O que é que eu vou fazer?' Faz a gente se sentir mal.

\section{Con. 3. Experiências decorrentes da Pesquisa}

Estão incluídas nesta categoria as experiências que decorrem da influência do pesquisador no contexto e da participação do estudante como informante na pesquisa.

Você estava me dizendo das mudanças na sala de aula devido à minha presença...

É essa brincadeira com as datas das provas. Ela não faz isso quando você está na sala. Quando ela diz alguma coisa, ela olha pra você pra ver se você a aprova. 


\section{Con. 4. Experiência do Tempo}

A experiência do tempo é uma constante nos relatos de estudantes. $\mathrm{O}$ tempo regula a atividade na sala de aula, sendo uma variável externa a ela que influencia tanto a prática de ensino do professor como a qualidade da aprendizagem do estudante. Experiências como falta de tempo encontram-se nesta subcategoria.

Ela explicou tudo muito bem, mas eu precisava de mais exercícios. Eu precisava trabalhar mais nisso porque era uma coisa nova, né? Mas, a gente não tinha tempo. Eu fiquei chateada dela ter passado para o próximo assunto tão depressa.

\section{Experiências Pessoais}

Esta categoria inclui experiências pessoais de diferentes tipos: (1) experiências relacionadas ao nível socioeconômico, (2) experiências anteriores de aprendizagem, (3) experiências da vida fora da sala de aula e (4) a experiência de trabalhar e estudar ao mesmo tempo.

\section{Pes. 1. Experiências por Nível Socioeconômico}

Nesta subcategoria se encontram as experiências que se referem ao nível socioeconômico e sua relação com o processo de aprendizagem.

Eu não sou rica. Mas meu pai não tem problemas financeiros, certo? Ele nos dá uma vida boa; nós temos nossa casa e ele sempre pagou por meus estudos, certo?

\section{Pes. 2. Experiências Anteriores}

Esta subcategoria se refere a experiências de aprendizagem de diferentes tipos e à forma pela qual elas influenciam o processo de aprendizagem. Essas experiências podem se referir a (1) experiências anteriores de aprendizagem de inglês, (2) experiências fora da sala de aula que tenham levado a resultados significativos de aprendizagem ou (3) a outros cursos que os estudantes relacionam com seu processo de aprendizagem atual. 
Eu vou explicar como é que eu sei para você. Este ponto a gente viu no semestre passado. Meu professor não foi o mesmo professor do resto dos meus colegas. Eu fiz Inglês III à noite e minha professora era como a ((nome da professora)), ela deu o livro todo.

Então, ((nome de colega)) fez sua apresentação que, aliás, foi fantástica. Ele falou sobre palavrões em inglês. Eu nunca vi coisa mais interessante. Eu até fiz um curso com ((nome de professor)) sobre gíria americana e a gente viu muitas dessas coisas, palavrões, verbos que a gente nem sonha que ((risos)) possam significar coisas tão diferentes.

\section{Pess. 3 Experiências da Vida Fora da Sala de Aula}

Experiências da vida pessoal que influenciam o processo de aprendizagem estão nesta subcategoria.

Olha, eu acredito que tudo influencia, mas eu acho que os problemas pessoais me afetaram muito porque, para ser honesto, por dois meses eu não falei com uma pessoa da minha família. Mas, problemas assim, eu tento deixar de lado quando eu venho para a aula. Mas, chega um ponto em que você não consegue mais.

\section{Pess. 4 Experiências no Trabalho e no Estudo}

Nesta subcategoria estão as experiências que se remetem ao trabalho e a sua influência no processo de aprendizagem.

Eu trabalho quatro horas por dia na Biblioteca Central e nas segundas, quartas e sextas-feiras eu trabalho das 18:00 às 23:00 em uma escola pública. Então, dá 29 horas de trabalho por semana. Por isso, fica difícil dedicar muito tempo ao inglês.

\section{Experiências Conceptuais}

Esta categoria contém as referências a experiências que expressam as concepções dos estudantes. Nela, as experiências resultam de outras anteriores 
e refletem expectativas. As concepções que compõem suas subcategorias são: (1) as concepções sobre o ensino de inglês e a relação ideal entre professor e aluno, (2) as concepções sobre a aprendizagem de inglês em geral, i.e., seus estágios e desafios, (3) e as crenças sobre seu próprio processo de aprendizagem, i.e., como eles percebem seu próprio processo de aprendizagem.

\section{Cpt. 1. Ensino de Inglês}

Nesta subcategoria estão as experiências que descrevem as crenças dos alunos sobre o ensino de inglês e a relação ideal entre professor e estudante.

Então, eu acho que ela quer que a gente pratique (a pronúncia) principalmente porque eu vejo que ela chama aqueles alunos mais calados. Praticar é também uma forma dela nos avaliar. Se eu fosse professor, era isso que eu faria.

Eu estou adorando tê-la como professora. No outro dia, eu até paguei um café para ela na cantina. Ela passa e conversa com a gente. E isso é bom porque faz com que a gente queira estar na sala dela. Ela até me perguntou se eu tinha visto o debate entre os candidatos. Eu gosto de estar na aula dela. Você não quer perder aula.

\section{Cpt. 2. Aprendizagem de Inglês}

Esta subcategoria contém as experiências que refletem as características e os desafios da aprendizagem de inglês.

Eu acredito que em geral para aqueles que estão aprendendo uma língua estrangeira, e eu também estou aprendendo espanhol, a estrutura é importante no nosso desempenho. No espanhol, eu não tenho tantos problemas porque eu acredito que domino mais a estrutura. Daí, eu não tenho tantos problemas. Mas, isso não quer dizer que seja mais fácil. Não é. Aprender uma língua estrangeira apresenta diferenças de todas as outras que você já sabe. Mas, o mais difícil é falar, não ter medo, dominar as estruturas e os sentimentos para não se sentir tão tímida. Eu acredito que é assim. 


\section{Cpt. 3. Aprendizagem Pessoal}

As experiências que refletem uma consciência do próprio processo de aprendizagem se incluem nesta subcategoria.

Eu acredito que é um tipo de aprendizagem interna, uhm, do aprendiz com ele mesmo. Certo? Internamente. Então, quando eu estou ouvindo, eu tenho mais contato. Eu venho para aula e mesmo se eu não me manifesto, eu estou lá quieta. Então, tem uma aprendizagem interna que acontece dentro de você, entende? Não quer dizer que você aprende por você, mas do que você tira das aulas, você começa a refletir sobre essas coisas com você mesmo. Entende? Eu acredito que é como está acontecendo. Eu começo a pensar e a refletir comigo internamente. Eu acredito que é assim.

\section{Cpt. 4. Responsabilidade}

Esta última subcategoria (dentro da categoria crenças) inclui as experiências em que os estudantes relatam a sua própria responsabilidade para com o processo de aprendizagem.

Sim, eu gosto dos exercícios. Embora às vezes ela manda fazer um montão de exercícios ((risos))... Mas, eu gosto porque ele significam mais tempo para eu estar em contato com a língua. Um semestre parece ter seis meses, mas de fato só tem quatro. E tem tanto feriado, então ... realmente se em casa você não tiver nada pra te empurrar pra estudar, é difícil. Então, é melhor ter trabalho de casa para te forcar a estudar em casa. Se não, nem vale a pena vir à aula.

\section{Experiências Futuras}

Esta é a última categoria indireta. A característica mais importante das experiências nela classificadas é a de se remeterem a planos para o futuro. Essas experiências podem se referir a aspectos cognitivos, sociais ou afetivos, mas revelam que há algo que ainda precisa ser trabalhado ou alcançado. Elas podem ser expressas em termos de (1) intenções, i.e., planos de ação que terão um efeito 
no desempenho do estudante, (2) vontades, i.e, a identificação de algo que pode não ser facilmente atingido, mas que, mesmo assim, ainda é importante para o processo de aprendizagem, (3) necessidades, identificação de uma área que merece uma atenção urgente ou (4) desejos, i.e., experiências que refletem metas mais distantes, tais como viajar ao exterior ou falar fluentemente.

\section{Fut. 1. Intenções}

Nesta subcategoria estão contidas as experiências que se remetem a planos de ação que vão contribuir para o processo de aprendizagem dos estudantes. Essas experiências normalmente aparecem logo depois da identificação de alguma limitação.

Então, agora, na escola, dentro da sala de aula, talvez, se a gente começar a falar com mais colegas, a gente se sinta mais seguro. Eu pretendo falar mais e superar minhas inibições e meu medo de falar.

\section{Fut. 2. Vontades}

Esta subcategoria se caracteriza por experiências nas quais os estudantes identificam alguma área na qual o seu desempenho possa/ precise ser melhorado. Entretanto, contrário à subcategoria Intenções, essas experiências se remetem a uma certa distância, i.e., são mais um reconhecimento de uma exigência/ necessidade do que um plano de ação propriamente dito.

Isso é o que eu estou tentando dizer ((risos)) se eu não conseguir esta fluência, eu não sei não... Eu estou fazendo outra língua e eu estou indo bem... e eu gosto disso, aprender línguas é interessante. Me atrai, eu já disse pra você. Mas, eu não quero ser um professor pela metade.

\section{Fut. 3. Necessidades}

Nesta categoria estão incluídas as experiências que se referem a necessidades, tais como a de desenvolver fluência e a de confrontar alguns tipos de sentimentos. Achar formas de superar questões como essas é o desafio implícito nessas experiências. 
Eficiência, o que você quer dizer com isso?

Ah! Eficiência quer dizer ser fluente no que está sendo proposto a você. Ela te dá uma atividade, você tem que descrever um lugar. Fluência para fazer isso é o que você precisa. Mas, talvez, devido a uma deficiência anterior ou à sua própria inabilidade, nesse caso, minha, a fluência necessária não acontece.

\section{Fut. 4. Desejos}

Na última subcategoria (dentro da categoria Metas) estão as experiências que se referem ao desejo dos estudantes de atingir alguma meta, que, de sua perspectiva, não passa de uma visão, um vislumbre. Por exemplo: viajar ao exterior ou ver-se como professor no futuro.

Então quando eu estava lá, de frente para sala, eu me vi no futuro, ensinando numa sala de aula, certo? Eu ensinando em uma escola ou no Centro de Extensão. Foi muito bom! Porque esse é o meu sonho: ser um professor. Então, quando eu me vi dando aula, me fez muito bem.

Ele falou de um conto no Festival no Tennessee onde as pessoas se encontram para contar estórias. Ele continuou falando em inglês e eu entendi tudo... me deu vontade de estar lá para ouvir as estórias ao vivo.

Termina, assim, a apresentação da categorização das experiências de estudantes. Torna-se evidente, pelos excertos, que são apenas uma fração limitada do que é vivenciado por eles, e que a experiência da aprendizagem de uma língua estrangeira é de fato um processo complexo e repleto de desafios que, se não forem superados, comprometerão o desempenho dos estudantes e, conseqüentemente, sua aprendizagem. A experiência de se estar em uma sala de aula para aprender uma língua estrangeira envolve questões da aprendizagem propriamente dita, mas há, também, conflitos de natureza social e afetiva, bem como as influências do contexto, das experiências pessoais, das relacionadas às concepções e ao futuro. O interessante é que todas são importantes para compreender o processo de aprendizagem e, mais ainda, que todas influenciam esse processo (MICCOLI, 2000, 2001) e que a maneira como essas influências podem explicar uma determinada experiência (MICCOLI, 2003). 
Uma síntese da versão final das categorias e subcategorias de experiências de estudantes em sala de aula é apresentada no Anexo II com o objetivo de ser mais fácil a visualização de toda a taxonomia. Mais ainda, essa taxonomia é apresentada com o objetivo de servir de modelo ou de ponto de partida para análise de experiências de estudantes em outros contextos.

\section{Conclusão}

Não é impossível buscar compreender o processo de aprendizagem de uma língua estrangeira em sala de aula, mas uma iniciativa nessa direção exige rigor nos procedimentos para garantir que o tratamento dos dados e os seus resultados sejam considerados confiáveis. Neste artigo, o objetivo foi apresentar os procedimentos adotados para o mapeamento e a categorização de experiências de estudantes que vêm orientando minhas pesquisas e as pesquisas sob minha orientação. Procedimentos que tomam tempo, mas que garantem a validade e a confiabilidade em pesquisas de natureza qualitativa. Além disso, a complexidade do processo de aprendizagem em sala de aula, que transparece através dos excertos que ilustram o processo de categorização de experiências em classes de língua inglesa é um objetivo indireto que precisa continuar a ser explorado e documentado por dois motivos. Primeiramente, pelo fato de a taxonomia apresentada poder vir a ser melhorada ou ampliada. Essa preocupação visa estimular mais a pesquisa de experiências de estudantes em diferentes salas de aula de língua estrangeira. O objetivo último dessa preocupação é conhecer melhor o processo de aprendizagem a fim de contribuir com professores e estudantes no processo de ensino e aprendizagem de uma língua estrangeira.

\section{Nota}

${ }^{1}$ Tradução livre de "protect our research and theory construction from our enthusiasms". 


\section{Referências}

ARAGÃO, R. C. Cognição, emoção e reflexão na sala de aula: por uma abordagem sistêmica do ensino/aprendizagem de inglês. Revista Brasileira de Lingüística Aplicada, v. 5, n. 2, p. 101-122, 2005.

ARAGÃO, R. C. São as histórias que nos dizem mais: emoção, reflexão e ação na sala de aula. 2007. 274f. Tese (Doutorado em Estudos Lingüísticos) - Faculdade de Letras, Universidade Federal de Minas Gerais, Belo Horizonte.

CONCEIÇÃO, M. P. Vocabulário e consulta ao dicionário: analisando as relações entre experiências, crenças e ações na aprendizagem de LE. 2004. Tese (Doutorado em Estudos Lingüisticos) - Faculdade de Letras, Universidade Federal de Minas Gerais, Belo Horizonte.

CUNHA, N. B. da. Experiências de aprendizagem: um estudo de caso sobre as experiências de estudo fora da sala de aula de alunos de Letras/Inglês em uma instituição particular de ensino superior. 2005. Dissertação (Mestrado em Estudos Lingüisticos) - Faculdade de Letras, Universidade Federal de Minas Gerais, Belo Horizonte.

DONATO, R.; McCORMICK, D. A sociocultural perspective on language learning strategies: the role of mediation. Modern Language Journal, v. 78, p. 453-464, 1994. FREITAS, M.A. Ensino em time por professoras-formadoras (inglês): um ritmo constante de fragmentações, fluidez, contradições. 2004. Tese (Doutorado em Letras) - UNESP, Assis.

LANTOLF, J. P. (Ed.). Sociocultural theory and second language learning. Cambridge: Cambridge University Press, 2000.

LATHER, P. Issues of validity in openly ideological research: between a rock and a soft place. Interchange, v. 17, n. 4, p. 63-84, 1986.

MATTOS, A. M A. Percepções de uma professora de inglês sobre sua sala de aula - uma visão êmica. 2000. 148f. Dissertação (Mestrado em Estudos Lingüisticos) - Faculdade de Letras, Universidade Federal de Minas Gerais, Belo Horizonte.

MICCOLI, L. A deeper view of EFL learning: students' classroom experiences. Claritas, v. 6, n. 3-4, p. 185-204, 2000.

MICCOLI, L. Reflexão crítica no processo de aprendizagem: o ponto de vista do aluno sobre experiências de aprendizagem de língua inglesa. In: MENDES, E. A. de M.; OLIVEIRA P. M. e BENN-IBLER, V. (Org.). O novo milênio: interfaces lingüísticas e literárias. Belo Horizonte: FALE-UFMG, 2001. p. 123-140. 
MICCOLI, L. Individual classroom experiences: a socio-cultural comparison for understanding EFL classroom learning. Ilha do Desterro, v. 41, n. 1, p. 61-91, 2003.

MICCOLI, L. Collective and individual classroom experiences: a deeper view of EFL learning in a Brazilian university. Revista Virtual da Linguagem-ReVel. Ano 2, n. 2, 2004. Disponível em: <www.revelhp.cjb.net>.

MICCOLI, L. Tapando buracos em um projeto de formação continuada à distância para professores de LE: avanços apesar da dura realidade. Linguagem e Ensino, v. 9, n. 1, p. 129-158, 2006.

MICCOLI, L. A experiência na Lingüística Aplicada ao ensino de línguas estrangeiras: conceituação, referências e implicações para a pesquisa. Revista de Lingüística Aplicada, v. 7, n. 1, 2007.

MILLER, G. A. The magical number seven, plus or minus two: some limits on our capacity for processing information. Psychological Review, v. 63, p. 81-97, 1956.

NEFFA, C. A cultura de avaliar de um professor/coordenador de disciplinas de LE: um estudo de caso no ensino médio. 180f. 2004. Dissertação (Mestrado em Estudos Lingüisticos) - Faculdade de Letras da Universidade Federal de Minas Gerais, Belo Horizonte.

PORTO, C. Percepções de professoras de Letras/Inglês sobre avaliação de aprendizagem: um estudo de caso. 185f. 2003. Dissertação (Mestrado em Estudos Lingüisticos) - Faculdade de Letras da Universidade Federal de Minas Gerais, Belo Horizonte. 


\section{ANEXO 1}

\section{Experiências em Sala de Aula de Estudantes de Inglês}

\section{Versão Preliminar}

\section{Experiências Cognitivas}

Cog. 1. Atividade/tarefa/apresentação de estudantes/atividade oral

Cog. 2. Objetivos/dúvidas/dificuldades/ perguntas

Cog. 3. Participação/não-participação

Cog. 4. Aprendizagem/evidência de aprendizagem/processo de aprendizagem

Cog. 5. Ensino/explicações do professor

Cog. 6. Estratégias

Cog. 7. Dever de Casa/quantidade de trabalhos/provas bimensais/testes

\section{Experiências Sociais}

Soc. 1. Interação

Soc. 2. Relação Interpessoal

Soc. 3. Ser aprendiz/papel do aprendiz

Soc. 4. Competição/riscos/conflitos/ exposição/incentivo/críticas

Soc. 5. Ser professor/papel do professor/poder do professor

Soc. 6. Grupos/pares/trabalho em grupo/membros/dinâmica

Soc. 7. Clima na sala de aula/ comportamento da sala de aula

Soc. 8. Estratégias

\section{Experiências Afetivas}

Afe. 1. Sentimentos positivos

Afe. 2. Sentimentos negativos

Afe. 3. Interesse/esforço/motivação ou falta de motivação

Afe. 4. Auto-estima/personalidade/ atitudes

Afe. 5. Professor/atitude/estresse

Afe. 6. Estratégias

\section{Experiências Contextuais}

Con. 1. Universidade/faculdade/fatores institucionais/situação de sala de aula

Con. 2. Situação profissional

Con. 3. Nível social

Con. 4. Influência do pesquisador/ pesquisa

Con. 5. Tempo

Con. 6. Status da língua estrangeira/ situação da língua estrangeira

Con. 7. Notas/escolha de lugar em sala de aula

\section{Experiências Pessoais}

Pes. 1. Nível social/família

Pes. 2. Aprendizagens anteriores

Pes. 3. Outras experiências de aprendizagem

Pes. 4. Outros cursos

Pes. 5. Vida pessoal/trabalho

Pes. 6. Vida escolar

\section{Experiências de Crenças}

Cre. 1. Processo de aprendizagem

Cre. 2. Ensino de línguas

Cre. 3. Processo de aprendizagem individual

Cre. 4. Relação ideal entre professor e aluno

Cre. 5. Aprendizagem de inglês

Cre. 6. Responsabilidade

\section{Experiências de Metas}

Met. 1. Ser professor

Met. 2. Pronúncia/fluência

Met. 3. Mais participação

Met. 4. Enfrentar medos 


\section{ANEXO 2}

\section{Experiências em Sala de Aula de Estudantes de Inglês Versão Final}

Experiências Diretas

Experiências Cognitivas

Cog. 1. Experiências nas atividades em sala de aula

Cog. 2. Identificação de objetivos, Dificuldades e dúvidas

Cog. 3. Experiências de participação e de desempenho

Cog. 4. Experiências de aprendizagem

Cog. 5. Percepção do ensino

Cog. 6. Experiências paralelas às atividades de sala de aula

Cog. 7. Estratégias de aprendizagem

\section{Experiências Sociais}

Soc. 1. Interação e relações interpessoais

Soc. 2. Tensão nas relações interpessoais

Soc. 3. Experiências como estudante

Soc. 4. Experiências do professor

Soc. 5. Experiências em grupos ou em dinâmicas de grupo

Soc. 6. Experiências em turma

Soc. 7. Estratégias sociais

\section{Experiências Afetivas}

Afe. 1. Experiências de sentimentos

Afe. 2. Experiências de motivação, interesse e esforço

Afe. 3. Experiências de auto-estima e atitudes pessoais

Afe. 4. Atitudes do professor

Afe. 5. Estratégias afetivas

\section{Experiências Indiretas}

\section{Experiências Contextuais}

Con. 1. Experiências institucionais

Con. 2. Experiências relativas à língua estrangeira

Con. 3. Experiências decorrentes da pesquisa

Con. 4. Experiência do tempo

\section{Experiências Pessoais}

Pes. 1. Experiências por nível socioeconômico

Pes. 2. Experiências anteriores

Pes. 3. Experiências na vida pessoal

Pes. 4. Experiências no trabalho e no estudo

\section{Experiências Conceptuais}

Cre. 1. Ensino de inglês

Cre. 2. Aprendizagem de inglês

Cre. 3. Aprendizagem pessoal

Cre. 4. Responsabilidade

\section{Experiências Futuras}

Met. 1. Intenções

Met. 2. Vontades

Met. 3. Necessidades

Met. 4. Desejos 